\title{
Editor's choice: sarcopenia or loss of muscle mass
}

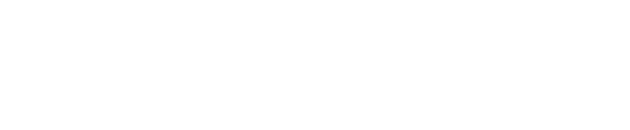

\section{Richard F Walker \\ Editor-In-Chief, Clinical Interventions in Aging}

To serve our readership better, some future editions of Clinical Interventions in Aging will contain the editor's comments and views on developing trends in the field of age management, with reference to recently published journal articles that address the issue at hand. Hopefully, these opinions will generate interest and comments from practitioners who deal with the clinical issues, treatments, and outcomes relevant to the topic chosen for each Editor's Choice. The first of these will address a chronic and universal effect of aging, ie, progressive changes in body composition, leading to sarcopenia or loss of muscle mass. Such changes during middle age and later life predispose individuals to functional limitations that become a common pathway for many pathological processes, and ultimately contribute to morbidity and death. The prevalence of sarcopenia, which may be as high as 30\% for individuals aged 60 years or older, will increase as the percentage of older individuals continues to grow in our population. However, because loss of skeletal muscle mass and strength begins relatively early in life, diagnosis of sarcopenia should not rely exclusively upon quantification of functional loss.

When considering the concept of declining structure and function during aging, it is important to determine if this is an inevitable and nonmodifiable aspect of senescence or whether it can be modified therapeutically. This basic question relates directly to and significantly influences clinical practice. There is probably no decline in structure and function more dramatic than the loss of lean body (muscle mass) over the decades of life. In fact, there may be no single feature of age-related decline more striking than this and negatively affecting more basic aspects of life, including ambulation, mobility, energy intake, overall nutrient intake and status, and respiration. These changes are directly related to reduced basal metabolic rate and progressive deficiencies in most other physiological functions that are responsible in a large part for increased weakness, falls, and fractures, leading to nursing home admission and loss of independence. Because of the link between sarcopenia during aging and disability, there is a continued need for research into the use of interventions that can prevent or at least partially reverse age-associated loss of muscle mass, including such therapies as resistance exercise, hormone replacement, and nutritional supplementation. To these ends, reference is now made to several papers recently published in Clinical Interventions in Aging that address this problem.

First of all was a thorough review of interventions by Walters et al ${ }^{1}$ entitled "Advantages of dietary, exercise-related, and therapeutic interventions to prevent 
and treat sarcopenia in adult patients: an update". This comprehensive review provides guides to a multitude of treatments for sarcopenia, ranging from diet to exercise to hormone replacement, and will serve practitioners as a useful reference to relevant research. Also is a review by Burton and Sumukadas ${ }^{2}$ which is focused on clinical management of the condition, entitled "Optimal management of sarcopenia". This paper complements and extends that previously published by Waters et al, and provides references to papers identifying the mechanisms of sarcopenia, its diagnosis, and potential clinical interventions for its treatment.

In addition to the review articles identifying exercise and nutritional status as important interventions for treating sarcopenia, the journal also contains research articles reporting clinical findings from application of these therapies. These include an article by Alfieri et $\mathrm{al}^{3}$ entitled "Functional mobility and balance in community-dwelling elderly submitted to multisensory versus strength exercises" and another by Ahmed and Haboubi ${ }^{4}$ entitled "Assessment and management of nutrition in older people and its importance to health".

More recently, the relationship between weight loss and transfer to high-level care or mortality was documented in a report by Woods et al. ${ }^{5}$ These authors studied a group of older patients who initially lived in low-level care facilities but were subsequently transferred to high-level care or died because of changes in body composition. While loss of muscle mass and reduced strength were characteristic findings in the study subjects, the acute affects of weight loss, primarily in the fat compartment, correlated with their adverse outcomes. It should be pointed out that while sarcopenia was not immediately responsible for the crises experienced by those subjects facing serious disease, quality of life, or even mortality, their weakened conditions associated with lean body mass undoubtedly initiated the cascade of failure leading to a negative outcome. The reason fat loss was significant in these cases was because it deprived individuals of their last energy stores, which were needed for even the most basic aspects of independent living.

While physical exercise has been shown to oppose sarcopenia, those with limited mobility may benefit from coordination exercise. Kwok et $\mathrm{al}^{6}$ reported that exercises with lower requirements for locomotive ability, such as coordination training and towel exercise, might be beneficial for sustaining and improving physical mobility and cognitive functioning in the elderly. Upon testing their hypothesis, Kwok et al found that coordination training was the most successful intervention, providing significant improvement in cognitive measures in their test subjects. This paper is entitled "Effectiveness of coordination exercise in improving cognitive function in older adults: a prospective study". Similar benefits of mild exercise to prevent falls associated with muscle loss were attributed to balancing exercise and reported by Kuptniratsaikul et $\mathrm{al}^{7}$ in their article entitled "Effectiveness of simple balancing training program in elderly patients with history of frequent falls". A review by Hanley et al entitled "Community-based health efforts for the prevention of falls in the elderly" was also included, providing a broad base of information to complement prevention and treatment of age-associated muscle loss. ${ }^{8}$

Finally, the practitioner is sometimes faced with the question of whether a diagnosis of sarcopenia or loss of strength is more appropriate for a specific patient. This issue was addressed in a research article by Woods et $\mathrm{al}^{9}$ entitled "Poor physical function in elderly women in low-level aged care is related to muscle strength rather than to measures of sarcopenia". Upcoming articles continue to report advances in the treatment of sarcopenia with various approaches. However, it is clear that we require greater understanding of the underlying mechanisms leading to sarcopenia, so that the cause(s) rather than its consequences may be targeted therapeutically. Nonetheless, current research indicates that significant strides are being made to develop specific interventions that will prevent disability and optimize independence, even to the extremes of old age.

\section{References}

1. Waters DL, Baumgartner RN, Garry PJ, et al. Advantages of dietary, exercise-related, and therapeutic interventions to prevent and treat sarcopenia in adult patients: an update. Clin Interv Aging. 2010;5:259-270.

2. Burton LA, Sumukadas D. Optimal management of sarcopenia. Clin Interv Aging. 2010;5:217-228.

3. Alfieri FM, Riberto M, Gatz LS, et al. Functional mobility and balance in community-dwelling elderly submitted to multisensory versus strength exercises. Clin Interv Aging. 2010;5:181-185.

4. Ahmed T, Haboubi N. Assessment and management of nutrition in older people and its importance to health. Clin Interv Aging. 2010;5: 207-216.

5. Woods JL, Iuliano-Burns S, Walker KZ. Weight loss in elderly women in low-level care and its association with transfer to high-level care and mortality. Clin Interv Aging. 2011;6:311-317.

6. Kwok TCY, Lam KC, Wong PS, et al. Effectiveness of coordination exercise in improving cognitive function in older adults: a prospective study. Clin Interv Aging. 2011;6:261-267.

7. Kuptniratsaikul V, Praditsuwan R, Assantachai P, Ploypetch T, Udompunturak S, Pooliam J. Effectiveness of simple balancing training program in elderly patients with history of frequent falls. Clin Interv Aging. 2011;6:111-117.

8. Hanley A, Silke C, Murphy J. Community-based health efforts for the prevention of falls in the elderly. Clin Interv Aging. 2011;6:19-25.

9. Woods JL, Iuliano-Burns S, King SJ, et al. Poor physical function in elderly women in low-level aged care is related to muscle strength rather than to measures of sarcopenia. Clin Interv Aging. 2011;6:67-76. 
Clinical Interventions in Aging

\section{Publish your work in this journal}

Clinical Interventions in Aging is an international, peer-reviewed journal focusing on evidence-based reports on the value or lack thereof of treatments intended to prevent or delay the onset of maladaptive correlates of aging in human beings. This journal is indexed on PubMed Central, MedLine, the American Chemical Society's 'Chemical Abstracts Ser-

\section{Dovepress}

Submit your manuscript here: http://www.dovepress.com/clinical-interventions-in-aging-journa

vice' (CAS), Scopus and the Elsevier Bibliographic databases. The manuscript management system is completely online and includes a very quick and fair peer-review system, which is all easy to use. Visit $\mathrm{http}: / /$ www.dovepress.com/testimonials.php to read real quotes from published authors. 